\title{
Qualitative Semi-Structured Interviews on the Experiences of Subacromial Impingement Syndrome Patients Receiving Shoulder Injections
}

\author{
Collins Ogbeivor ${ }^{1 *}$, Suresh Bandaru² and Carl Milton ${ }^{2}$ \\ 'Chief Investigator, Department of Rehabilitation, Consultant Physical Therapist, John Hopkins Healthcare Aramco Dhahran, Kingdom of Saudi \\ Arabia. \\ ${ }^{2}$ Principal Investigator, Department of Physiotherapy, Extended Scope Physiotherapy, East Sussex Hospital Trust, Hastings, UK.
}

*Address for Correspondence: Collins Ogbeivor, Chief Investigator, Department of Rehabilitation, Consultant Physical Therapist, John Hopkins Healthcare Aramco Dhahran, Kingdom of Saudi Arabia. E mail: collins.ogbeivor@jhah.com

Received: 28 July 2020; Accepted: 25 August 2020; Published: 29 August 2020

Citation of this article: Ogbeivor C, Bandaru S, Milton C (2020) Qualitative Semi-Structured Interviews on the Experiences of Subacromial Impingement Syndrome Patients Receiving Shoulder Injections. Rea Int J of Ortho and Rheum. 1(1): 001-0013. DOI: $10.37179 /$ rijor.000001.

Copyright: (C) 2020 Ogbeivor C, et al. This is an open access article distributed under the Creative Commons Attribution License, which permits unrestricted use, distribution, and reproduction in any medium, provided the original work is properly cited.

\footnotetext{
ABSTRACT

Objectives: To establish the experiences of subacromial impingement syndrome (SAIS) patients receiving lateral versus posterior shoulder injections associated with better clinical outcomes.

Design: A semi-structured qualitative interview to investigate SAIS patients' experiences of receiving shoulder injections

Settings: Out-patients community musculoskeletal service

Sample: 20 participants for the semi-structured qualitative interview.

Results: From the semi-structured interviews, the five major themes which emerged are expectation of treatment, treatment outcome, procedure, patient education and access to treatment. Participants felt that their shoulder symptoms improved not only because of the effect of the cortisone injection, but also because of education about their treatment, exercise information, the professionalism, experience, and skills of the injecting clinicians, access to treatment as well as good customer service. These views were expressed by those who had complete pain relief and those who still had some residual pain.

Conclusion: Our study highlights the importance of patients' education, their involvement in the treatment, exercise information, the professionalism, experience and skills of the injecting clinicians and access to treatment for improving the patients' overall experiences and clinical outcomes. In view of these benefits, future studies should therefore consider the use of qualitative research method in the investigation of musculoskeletal conditions such as shoulder conditions.

Keywords: Subacromial impingement syndrome, shoulder injections, cortisone injection, semi-structured interviews, qualitative study, patient experience.
} 
Citation: Ogbeivor C (2020) Qualitative Semi-Structured Interviews on the Experiences of Subacromial Impingement Syndrome Patients Receiving Shoulder Injections. Rea Int J of Ortho and Rheum. 1(1): 001-0013. DOI: 10.37179/rijor.000001.

\section{Introduction}

Anterior, posterior, and lateral approaches of subacromial injections are described in the literature [1-4] with the latter two most used [3]. Previous randomised controlled trials (RCTs) [2, 5-7] and one comparative study (Sardelli \& Burks) have investigated needle placements in subacromial impingement syndrome (SAIS) using a reference standard. However, none of these studies directly evaluates the experiences of these patients regarding lateral or posterior needle placement in SAIS. Despite these limitations, these studies provide some useful information for future research.

There is paucity of evidence in the subjective experience of SAIS patients receiving subacromial injections. One recent UK study describes the experience of patients' living with a symptomatic rotator cuff tear (RCT) their symptoms, the impact upon their daily lives and the coping strategies utilized by these patients [8].

A previous qualitative study has explored patients' experiences with frozen shoulder and their treatment with Bowen technique [9], and a semi-structured qualitative study investigated the patients' perceptions and priorities regarding frozen shoulder [10].

A study on the impact of psychological factors on the outcome of physiotherapy in the management of shoulder pain that reported that patient's expectations of their treatment results contributed to their overall clinical outcomes [11].

Although these studies have provided useful information on the qualitative experience patients with a shoulder pathology, they lack information on the experiences of patients with SAIS receiving cortisone injection.

To our knowledge, just one study [12] was found that investigated the experiences of patients with supraspinatus tendinitis who had received both physiotherapy and cortisone injection or had undergone open or arthroscopic shoulder surgery. The study involved 26 participants aged 43-63 and interviews were through focus groups.

Although this study provides information on patients' experiences of shoulder problems before and after intervention using focus groups interviews, only 3 out of the 26 participants who were interviewed were treated with cortisone injection after having physiotherapy.

While the study's findings are generalizable to patients with supraspinatus tendonitis receiving physiotherapy or surgical interview, they are not generalizable to SAIS patients receiving cortisone injection because of the small number ( 3 out of 26) of those involved in the study. However, the study provides a good platform to conduct future qualitative interviews regarding SAIS patients' experiences of receiving subacromial injection.

To our knowledge and despite extensive literature search, no study has explored the experiences of patients with SAIS receiving lateral or posterior approach to shoulder injection in normal clinical situations. This study, therefore, aims to establish the experiences of SAIS patients receiving these injections.

\section{Research Question}

What are the experiences of patients with subacromial impingement syndrome receiving shoulder injections?

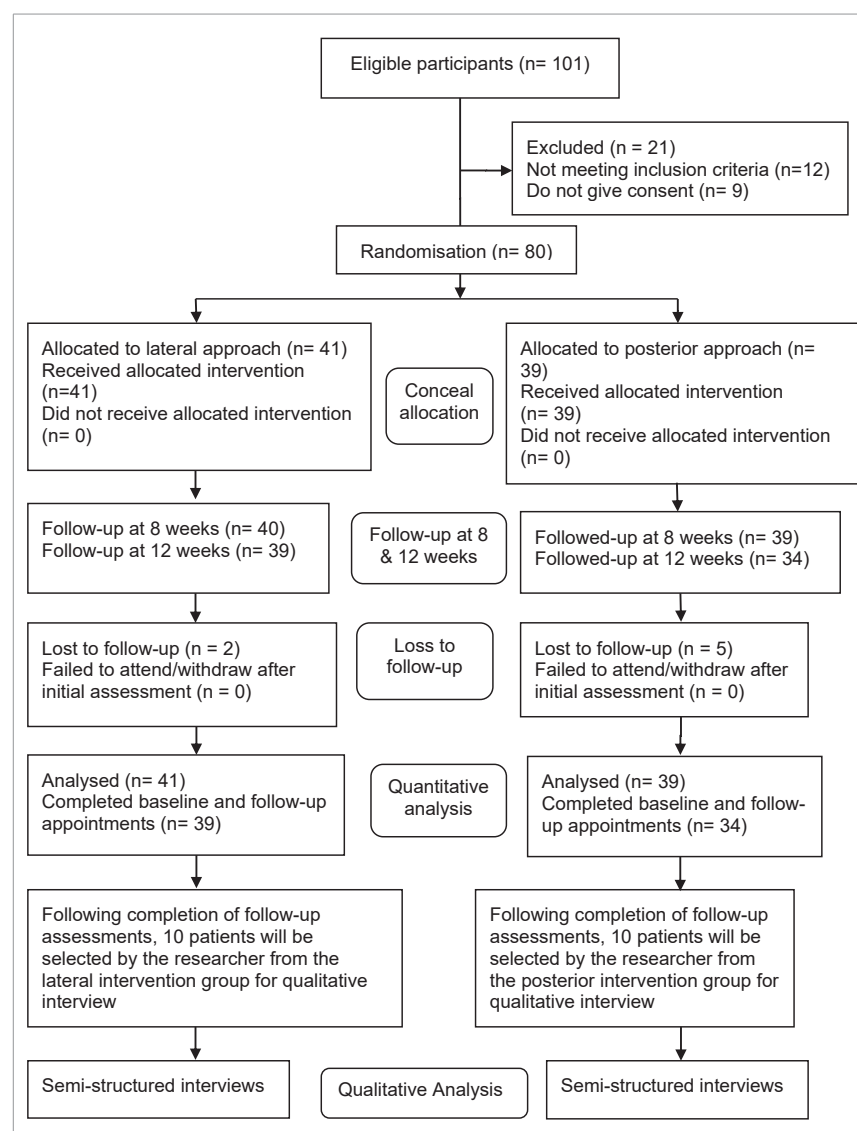

Figure 1: Flow chart showing movements of patient through the trial.

\section{Methods}

This study used a mixed methods approach that combines both a quantitative (phase 1) [4] and a qualitative (phase 2) approach as the research design. Ethical approval for the study was granted in April 2014 by National Research Ethics Committee (Ref No: 14/LO/0406). The researcher, who acted as Chief Investigator, and two Specialist Physiotherapists (Extended Scope Physiotherapists) were involved in the study. The Specialist Physiotherapists and the administrative staff involved in the study received training on the study protocol. The results of the qualitative semi-structured interviews are presented in this paper. See (Figure 1) flow chart showing movements of patient through the trial.

\section{Study Settings}

The study setting was at a large Community Musculoskeletal (MSK) service. All the participants recruited to the study were from a population of patients attending a community (MSK) service. This service receives referrals from 33 GP practices in the area.

\section{Participants' Selection Criteria}

Inclusion and exclusion criteria for the diagnosis of SAIS and for the study are documented in (Tables 1,2), respectively. All patients in the study gave written informed consent prior to the study.

\section{Recruitment of Potential Participants}

The recruitment process took place over a year between August 
Citation: Ogbeivor C (2020) Qualitative Semi-Structured Interviews on the Experiences of Subacromial Impingement Syndrome Patients Receiving Shoulder Injections. Rea Int J of Ortho and Rheum. 1(1): 001-0013. DOI: 10.37179/rijor.000001.

Table 1: Diagnosis Criteria for SAIS.

\begin{tabular}{|c|c|}
\hline Inclusion Criteria & Exclusion Criteria \\
\hline $\begin{array}{l}\text { Patients aged } 18 \text { and above } \\
\text { Shoulder pain localised to the acromion } \\
\text { Pain with active arm elevation } \\
\text { Positive painful arc between } 60^{\circ} \text { and } 120^{\circ} \text { of } \\
\text { abduction } \\
\text { Positive impingement test-Neer's sign or Hawkins } \\
\text { Kennedy } \\
\text { No evidence of referred pain from cervical spine }\end{array}$ & $\begin{array}{l}\text { Patients below } 18 \text { years of age } \\
\text { History of: } \\
\text { - Current Pregnancy } \\
\text { - Spinal or shoulder surgery (last } 6 \text { months) or joint replacement } \\
\text { - Current Spinal or upper limb fracture } \\
\text { - Previous hydrocortisone injection in the last } 4 \text { weeks } \\
\text { - Shoulder dislocation/ instability } \\
\text { - Current Frozen shoulder } \\
\text { - Acromioclavicular joint arthritis } \\
\text { - Os acromiale } \\
\text { - Bony metastases } \\
\text { Clinical findings of presence of positive: } \\
\text { - External rotation lag sign } \\
\text { - load and shift test } \\
\text { - Sulcus sign } \\
\text { - Active compression labral test } \\
\text { Reproduction of shoulder symptoms during active cervical movements } \\
\text { Reproduction of shoulder symptoms on movements of the cervical or thoracic spine rather than } \\
\quad \text { shoulder movement } \\
\text { Radiographic evidence of calcific periarthritis }\end{array}$ \\
\hline
\end{tabular}

Table 2: Inclusion and Exclusion Criteria for the Study.

\begin{tabular}{|c|c|}
\hline Inclusion Criteria & Exclusion Criteria \\
\hline Patients 18 years and above & Patients under 18 years of age \\
\hline $\begin{array}{l}\text { They fulfil the eligibility criteria for } \\
\text { SAIS }\end{array}$ & $\begin{array}{l}\text { Did not fulfil the eligibility criteria } \\
\text { for SAIS }\end{array}$ \\
\hline Able to give informed consent & Failure to consent \\
\hline $\begin{array}{l}\text { Eligible for lateral and posterior } \\
\text { routes of subacromial injection }\end{array}$ & $\begin{array}{l}\text { Not eligible for lateral and posterior } \\
\text { routes of subacromial injection }\end{array}$ \\
\hline $\begin{array}{c}\text { Patients with no contraindication to } \\
\text { cortisone injection such as: } \\
\text { - sepsis, fracture sites, prosthetic } \\
\text { joint and uncontrolled blood glucose } \\
\text { levels }\end{array}$ & $\begin{array}{l}\text { Patients with contraindication to } \\
\text { cortisone injection such as: } \\
\text { - sepsis, fracture sites, prosthetic } \\
\text { joint and uncontrolled blood } \\
\text { glucose levels }\end{array}$ \\
\hline
\end{tabular}

2014 and August 2015. When the first musculoskeletal appointment was posted to the patient, a separate envelope containing a letter of invitation to take part in the study was also sent. The invitation pack contained a letter of invitation with a Patient Information Sheet (PIS) and two consent forms (for the quantitative part and the qualitative interview). In the PIS, it was clearly stated that involvement in the study was voluntary and that participants were free to withdraw from the study at any time.

Participants who were interested in taking part in the study but had further questions been encouraged to contact the researcher via a study mobile number or postal address. Participants were asked to read the PIS before attending their first musculoskeletal appointment if they wished to participate. On attending their appointment, they had an opportunity to ask questions and were asked to sign the consent forms. Potential participants who fulfilled the eligibility criteria following screening by the assessing Extended Scope Physiotherapist and provided written informed consent were then recruited into the study.
For the qualitative semi-structured interviews, participants were identified from those who participated in the RCT study and who gave consent to be contacted to participate in the qualitative study (Appendix 1). If they were, they were re-consented verbally and a date and time for the semi-structured interview concerning their experiences of the subacromial injections was arranged.

\section{Sampling and Selection Method}

Purposive, convenience sampling as suggested by Patton (2002) was used to identify participants from those that have participated in phase 1 of the quantitative study [4] and who gave consent to be contacted to participate in the qualitative study (Appendix 1). The interviews were linked to normal practice follow-up times. Participants were selected by the Chief Investigator from the list of those who had complete pain relief and those who had residual symptoms after the cortisone injection. The Chief Investigator identified 10 participants from each group of the subacromial injection routes and they were contacted by telephone to first check that they were still willing to participate in an interview. If they were, they were re-consented verbally and a date and time for the semistructured interview concerning their experiences of the subacromial injections was arranged. Participants with different gender, ages and socio-economic backgrounds including negative responders to subacromial injections were selected to offer a broad understanding of the topic being studied [13-15] and allowed maximum variation in the data that was collected [16].

\section{Date Collection Methods}

In normal practice, patients who have had injection therapy are contacted by telephone to evaluate its outcomes. A semi-structured interview was used as a method of gathering data. This took the form of open-ended questions to encourage the participants to tell their stories. The interview date, time and convenience were mutually agreed by the researcher and the respondents prior to the interview.

The researcher conducted interviews after participants took 
part in the quantitative research. All interviews were conducted by telephone conversation and were centred on symptom relief, aggravation and patient care following an experience of subacromial injection. Interviewees were allowed the opportunity to give detailed accounts of their experiences with individual interviews lasting approximately 20 - 30 minutes. Interviews were Dictaphonerecorded with the consent of the interviewee and field notes were taken by the Chief Investigator during and following the interviews to contextualize the data [16]. All data were transcribed verbatim. We also used respondent re-validation by sending the transcript back to the participants to ensure that its contents matched what had been said.

\section{Development of Interview Guide and the Process}

To facilitate the interview process, an interview guide (Appendix 2 ) was developed and the questions were centered about the research questions to ensure that important and relevant areas of the aims of the study were covered during the interview.

\section{Plan of Analysis}

Data analysis took the form of the Framework Method reported by Ritchie and Lewis (2003). This systematic and well-defined process of sifting, indexing, and coding material according to main issues and themes, was linked to five stages thematic approach outlined by (Ritchie \& Spencer 1994, Ritchie \& Lewis 2003). The key stages involved in framework include familiarization, identifying a conceptual framework or indexing, labelling the data by themes and subthemes, creating thematic charts, descriptive and classification analysis and dimensions and explanatory accounts.

\section{Results}

From the interviews conducted, five major themes associated with experiencing subacromial injection by the participants with SAIS were identified from the analysis. They included expectation of treatment, treatment outcome, procedure, patient education and access to treatment.

\section{Sample Demographic}

Data collection occurred between March 2015 and June 2015. Eighty participants completed phase 1 of the quantitative study. A purposive sample of 20 was chosen from the above sample, to participate in a semi-structured interview. They included 9 males and 11 females aged between 18 to 65 years and above $(n=20)$. Twelve had a lateral approach and 8 had a posterior approach of subacromial injection. They all participated in the study (See Table 3). (See Table 4) for characteristics of the participants.

\section{Hierarchical Framework Analysis Approach (Ritchie \& Lewis 2003)}

The 20 interviews were tape recorded and transcribed verbatim. Using MAXQDA as the data management tool the 20-textual data or transcripts were organised and categorised using general comments from the interview. (Figure 3) shows a diagrammatic representation of the hierarchical framework analysis model proposed by Ritchie \& Lewis (2003), used to guide the analysis in this study.

\section{Familiarization Stage (Identifying Initial Themes and Concepts)}

This is the first and essential point to qualitative data analysis stage. During the familiarisation stage of this study, the researcher listened to the audio recording of the interviews, read through the interview transcripts and observation notes and then made notes (memos) of important issues and recurrent themes (such as improvements) that were mentioned by the research participants. Initial descriptive items used by the participants to express their experiences of receiving subacromial injections were noted.

\section{Identifying Conceptual Framework or Indexing}

This stage involved indexing of the phrases and identifying links between categories, grouping them thematically and then sorting them according to different levels of main and subthemes. This process was informed by the methods shown in (Figures 2,3). In this study, the overall index contained 72 subthemes or categories that were grouped under just 10 main substantive themes or headings. The key themes and subthemes were then systematically numbered with the help of MAXQDA to produce an indexing reference (see Figure 4).

\section{Labelling or Tagging the Data by Themes and Subthemes}

After constructing the initial conceptual framework or indexed data, this stage involved applying the indexed data in (Figure 4) to the appropriate sentences or paragraphs in the interview transcripts (raw data). The process shows which theme or concept is being mentioned or referred to within a section of the interview transcript. (Figure 5) is an example of labelling or tagging of the indexed themes and subthemes. In this example, the text is a small excerpt of the participant's transcript (0014P) that was cross-labelled and indexed.

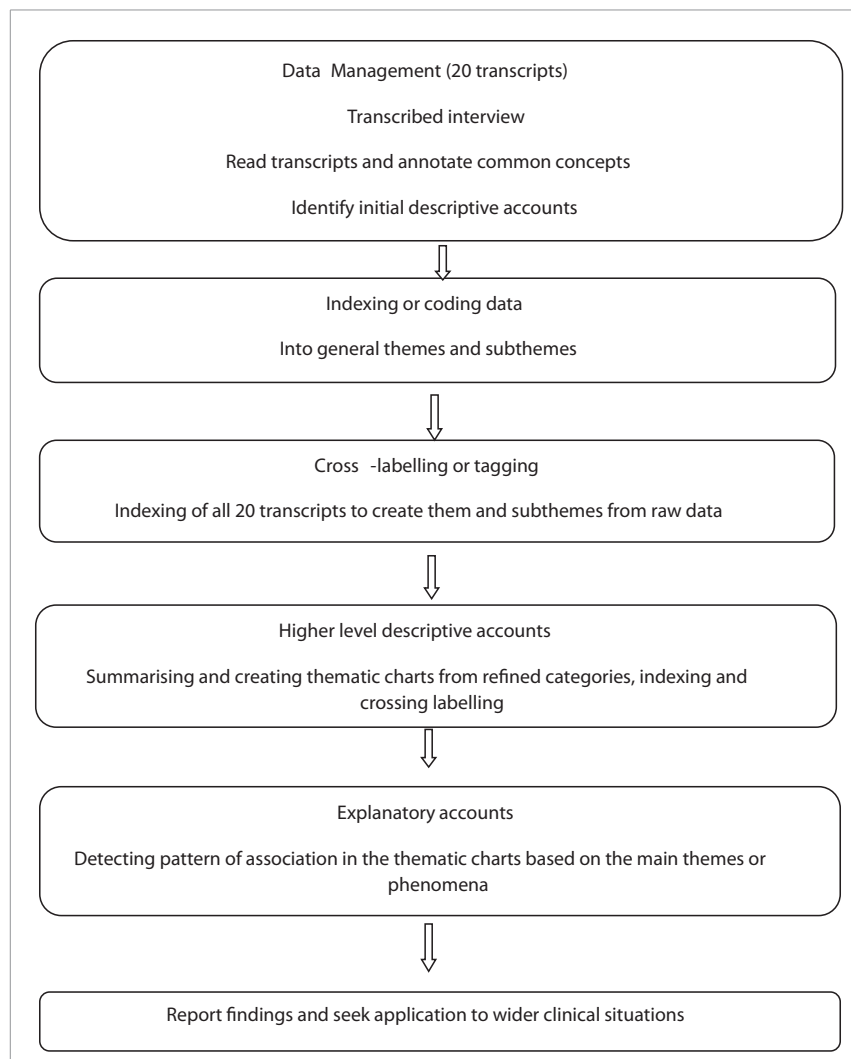

Figure 2: An illustration of the iterative and hierarchical process of qualitative data analysis adopted for this study. 


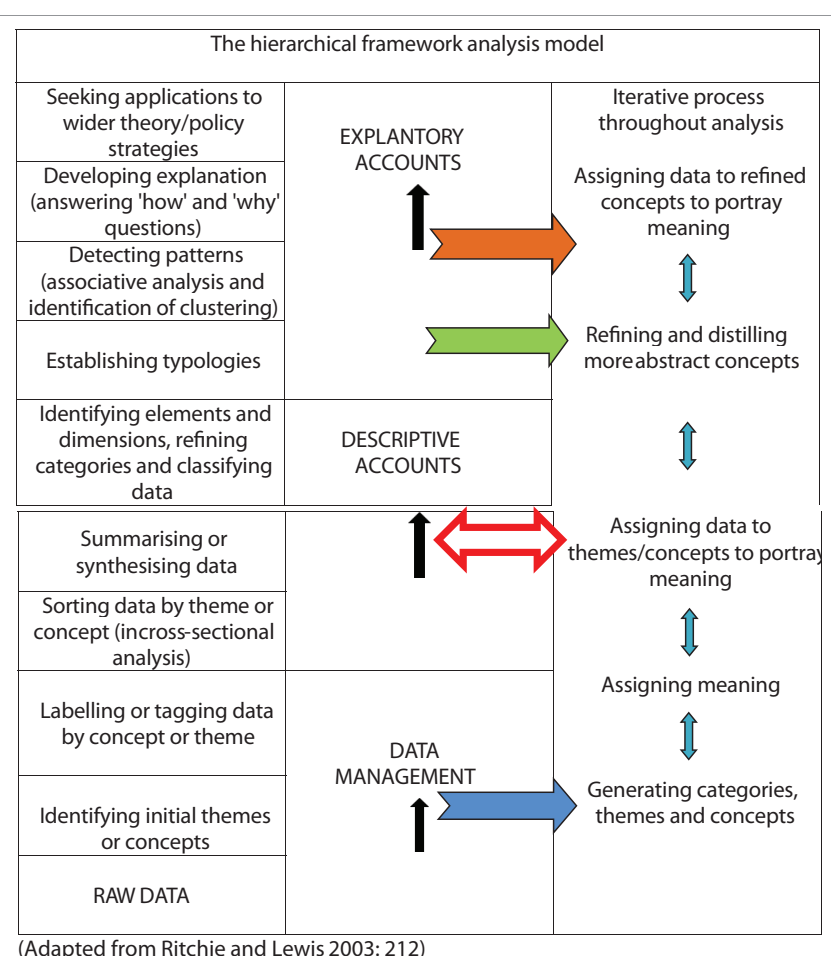

Figure 3: A diagrammatic representation of the hierarchical framework analysis model used to guide the data analysis.

\section{Creating Thematic Charts}

This stage of the analytical data abstraction involves identifying common concepts or patterns across the participants' interview transcripts and grouping them into categories and charts using the thematic charts (Ritchie \& Lewis 2003). MAXQDA was used to generate the thematic matrices or charts for some key themes and subthemes, which were displayed in a single spreadsheet or code matrix browser. An example of the layout of the thematic chart taken from the matrix browser (Appendix 3) is shown in (Table 5). This example represents two participants, 0047L and 0031P. Excerpts from the analysis of their interview transcripts are shown under each subtheme in rows 2.1 to 2.5 . They include the exact accounts that the participants gave about their injection experience.

\section{Descriptive and Classification Analysis - Identifying Elements and Dimensions, Refining Categories, Classifying Data}

This stage involved identification of a particular theme, refining of categories, and assigning groups of categories to 'classes' usually at a higher level of abstraction (Ritchie \& Lewis 2003). (Table 6) is an excerpt from participant's $0052 \mathrm{P}$ transcript and is an example of using the Framework approach for descriptive and classification analysis.

(Table 7) is an example of the descriptive and classification process performed for the subthemes. Column A is the participant unique identification number, column $\mathrm{B}$ contains the original quotes from the transcripts, while column $\mathrm{C}$ is a close description of the participant's original quotes, but now contains mainly the relevant elements of the initial quotes. Column D is a higher level of categorisation where elements detected have been interpreted in a more conceptual manner to provide a new meaning. For example, in column C "unsure about the pain" from (participant 0014P) and "Lack of knowledge about the problem" from (participant 0047L) were both categorised in column D as uncertainty about the cause of pain.

Finally, after application of the above process of analysis in (Table 7) to all the main thematic charts and reviewing the descriptive items in column D above, a descriptive list of discovered items that represent new categories were compiled. They represent the participants' concepts regarding their experiences of receiving subacromial injections from injecting ESP's working in normal community practice. Examples of descriptive items include: Anxiety or uncertainty about the cause of pain, sense of reassurance following education, expectation of pain relief, clinician's skill, knowledge, and experience, as well as receiving clear information about the problem, treatment, and care.

\section{Dimensions and Explanatory Accounts}

After investigating the descriptive list, identification of specific conceptual labels or a number of associated features took place. This resulted in the creation of eight new or key dimensions and themes which consist of: shoulder pain issues, diagnosis and prognosis of the problem, interaction with the injecting clinicians, information received, participant's expectation, treatment location, referral system, and outcome of treatment.

These main categories were then re-sorted and revised generating five main final themes. They include expectation of treatment, treatment outcome, procedure, patient education and access to treatment. Finally, explanation of the core themes was achieved using the theoretical framework of the research to tell the story that participants with SAIS gave about their experiences of receiving subacromial injection performed by ESPs working in a community setting. This is discussed in the next section.

\section{Main Themes}

\section{Expectation of Treatment}

Participants that were interviewed said that the onset of shoulder pain could be gradual or sudden and was either constant or intermittent. The participants mentioned that the reason why they had cortisone injection was mainly because they were in pain but also because they had limited shoulder movement. Pain relief was a key expectation of the participants because they confirmed that after they had received the subacromial cortisone injection they expected their shoulder pain to subside or resolve completely.

This is to enable them to use their shoulder better and without much pain so they could perform their normal everyday activities more easily such as lifting a kettle, changing gear, and opening a door. Some of the participants interviewed said their expectation of complete pain relief was achieved after receiving the injection into their shoulder while for some it was only partial (that is they still had some residual pain). For example, two patients commented:

"I think actually, I believe our shoulder was quite inflamed and I had it for quite a long time and it probably restricted our movement quite a lot and the injection just improved all of that". (0047L, 64-yearold female) 
Citation: Ogbeivor C (2020) Qualitative Semi-Structured Interviews on the Experiences of Subacromial Impingement Syndrome Patients Receiving Shoulder Injections. Rea Int J of Ortho and Rheum. 1(1): 001-0013. DOI: 10.37179/rijor.000001.

\author{
1. Expectation of treatment \\ 1.1 Pain relief \\ 1.2 Better shoulder movement \\ 1.3 A complete cure or pain relief \\ 1.4 Expectation not met \\ 1.5 Self-healing- natural resolution \\ 1.6 Not sure whattreatment they were going to receive \\ 1.7 Other issues - physiotherapy or cortisone injection
}

2. Information and advice from the clinicians

2.1 Explanation of every aspect of the treatment and care

2.2 Not knowing what was going in the shoulder

2.3 Explaining what was goingon the shoulder and what to do about it

2.4 Been listened to and involved in the treatment

2.5 Exercise information

2.6 General treatment information

2.7 Explanation of treatment procedure

2.8 Other issues

3. Participants perception of the injecting ESP and the injection proce dure 3.1 Politeness and how knowledgeable the clinician was

3.2 Caring and helpful attitude of the clinician

3.3 Treated as an individual

3.4 Injection technique

3.5 Professionalism of the injecting clinician

3.6 Other issues

4. Description of pain and associated factors

4.1 Duration of pain - 2 weeks, 18-24 months

4.2 Onset of pain-gradual

4.3 Nature of pain- constant

4.4 Pattern of pain- 24 months

4.5 Complete resolution of pain or residual or orgoing symptoms

4.6 Location of the pain

4.7 Inflammation of the shoulder

4.8 Stiffness of the shoulder

4.9 Pain on movement of the shoulder at work and during sports

4.10 Sleep disturbance due tøighttimepain

4.11 Other issues-frustration

5. Understanding of where pain is coming from

5.1 Not sure where the problem is coming from

5.2 Not knowing what was going in the shoulder

5.3 Query diagnosis-? impingement or tendonitis or full tear

5.4 Researching where the pain is coming from

5.5 Self-diagnosis- frozen shoulder

5.6 Other issues - related to elbow
6. Access to treatment

6.1 Easy parking

6.2 Near distance and within walking distance

6.3 Referral system

6.4 Quick appointment and seen sooner

6.5 Location and environment

6.6 The ease and convenience

6.7 Phone call received about appointment

6.8 Other issues - seeking partne'rs opinion on what to do

7. Outcome perceived after receiving treatment

7.1 Improvement- gradual or immediate

7.2 Better because of the cortisone effect

7.3 Effect on movement- better or same

7.4 Better within few weeks or months

7.5 Not been treated as just another candidate

7.6 The injection helped after 2 weeks

7.7 The way the injection was performed

7.8 Satisfaction/Efficient treatment

7.9 Referred to another specialism

7.10 Other issues - it did not hurt, I did not feel pain

8. Going to the doctor - seeking help from the GP 8.1 GP took about 3-4 weeks to do the referral 8.2 Got appointment 2 weeks after GP referred

8.3 GP's expectation- patient to have cortisonepr surgery or a scan 8.4 GP's diagnosis- agreement / disagreement

9. Physiotherapy/cortisone referral suggested

9.1 GP initiated physiotherapy

9.2 Family and friend suggested physiotherapy

9.3 Other issues - injection suggested by some friends including GP

10. Service delive ry

10.1 Prompt and friendly service

10.2 Good customer service

10.3 Not kept waiting for an appointment or before been treated

Figure 4: Indexing - major themes and subthemes identified during the interview.

"I thought it was going to clear it, but my arm still aches and there is still a bit of pain when I use it in different directions if you know what I mean, it jerks then it hurts". (0029L 70-year-old male)

Some of the participants who had ongoing symptoms asked if they could have some physiotherapy and where been offered, while others were given the option of physiotherapy and they accepted. Very few who did not improve following the injection were further investigated with MRI or ultrasound scan and referred onward for surgical considerations.

\section{Treatment Outcome}

A key theme from the interviews was the outcome of the cortisone injection. In this study some of the participants who said their pain got better after the injection said that it was certainly due to the efficacy of the cortisone injection. One of the participants who had the injection via lateral route said:

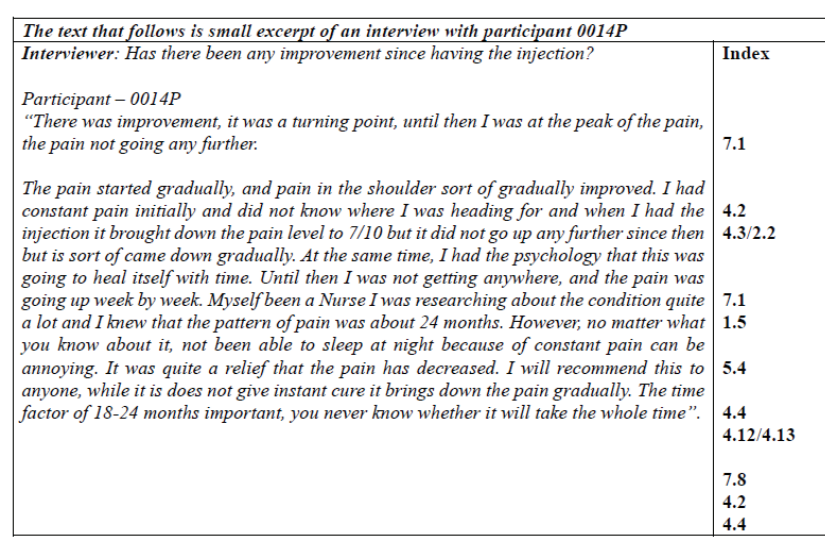

Figure 5: An Example of Labelling or Tagging of the Indexed Themes and Subthemes of part of an Interview Transcript of a Participant.

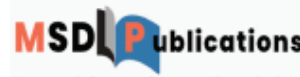

Research is creating new knowledge 
Citation: Ogbeivor C (2020) Qualitative Semi-Structured Interviews on the Experiences of Subacromial Impingement Syndrome Patients Receiving Shoulder Injections. Rea Int J of Ortho and Rheum. 1(1): 001-0013. DOI: 10.37179/rijor.000001.

"Yes definitely. It's been about $98 \%$ okay because of the cortisone injection" (0058L 36-year-old male).

Some of the participants said that the cortisone injection provided complete and immediate pain relief, while some mentioned it was a gradual process. Those who said it was a gradual process also mentioned that their shoulder movement improved in a gradual fashion as well. For participants who improved (either through a lateral or posterior route of subacromial injection), the effectiveness of the cortisone injection in reducing pain meant their shoulder movement improved also. For example, two participants who received the injection via lateral route commented:

Table 3: Description of Interview Participants.

\begin{tabular}{|c|c|}
\hline Characteristic & Number \\
\hline $\begin{array}{c}\text { Injection Location } \\
\text { Lateral } \\
\text { Posterior }\end{array}$ & 11 \\
Gender & 9 \\
Male & \\
Female & 10 \\
Age (years) & 10 \\
$18-40$ & \\
$41-65$ & 3 \\
Above 65 & 14 \\
Responders & 3 \\
\hline Complete pain resolution & 10 \\
Improved, but with residual pain/No improvement & 10 \\
\hline
\end{tabular}

Table 4: Characteristics of the Participants.

\begin{tabular}{|c|c|c|c|c|c|}
\hline Participant ID & Participant Gender & Age in years & Group & Duration of symptoms (weeks) & Responders \\
\hline $002 \mathrm{~L}$ & Male & 43 & Lateral & 12 & Improved, but with residual pain \\
\hline $007 \mathrm{~L}$ & Female & 64 & Lateral & 36 & No improvement \\
\hline 0014P & Male & 47 & Posterior & 52 & Complete pain resolution \\
\hline $0025 \mathrm{P}$ & Female & 31 & Posterior & 12 & Complete pain resolution \\
\hline $0027 \mathrm{~L}$ & Female & 58 & Lateral & 52 & Complete pain resolution \\
\hline 0028L & Female & 71 & Lateral & 208 & Improved, but with residual pain \\
\hline 0029L & Male & 70 & Lateral & 12 & Improved, but with residual pain \\
\hline 0031P & Female & 54 & Posterior & 26 & Complete pain resolution \\
\hline 0032L & Male & 55 & Lateral & 26 & No improvement \\
\hline $0034 \mathrm{P}$ & Female & 55 & Posterior & 20 & Complete pain resolution \\
\hline 0035P & Female & 49 & Posterior & 208 & Improved, but with residual pain \\
\hline 0038P & Male & 54 & Posterior & 16 & No improvement \\
\hline 0039L & Female & 67 & Lateral & 26 & Complete pain resolution \\
\hline 0045L & Male & 55 & Lateral & 20 & Improved, but with residual pain \\
\hline 0047L & Female & 64 & Lateral & 16 & Complete pain resolution \\
\hline 0049P & Male & 38 & Posterior & 20 & Complete pain resolution \\
\hline 0052P & Male & 43 & Posterior & 54 & Improved, but with residual pain \\
\hline 0055L & Female & 51 & Posterior & 13 & No improvement \\
\hline 0056P & Male & 51 & Posterior & 5 & Complete pain resolution \\
\hline 0058L & Male & 36 & Lateral & 78 & Complete pain resolution \\
\hline
\end{tabular}

"Because after you've had the injection you are back to completely normal again, you are free from pain and you are free from everything" (0039L 67-year-old female).

"Yes, it gave me more movement the pain is still there, still throbbing, but now not as severe and it has at least given me 30-40\% more movement in the last 5 or 6 weeks. (0045L 55-year-old male)

\section{Procedure}

Phrases like "it was brilliant!", "very professional”, "1st class!", "particularly good indeed" and "10 out 10" were used to describe how participants felt about the injection technique. These comments involved both groups of the study and included those who had complete pain relief and those who had residual pain.

In this study all the injections were performed (using patient group direction guidelines) by two injecting clinicians who were trained and had adequate experience and skills. All injections were performed after obtaining both verbal and written informed consent from the participants. Most participants confirmed that the injecting clinicians were knowledgeable of the injection procedure and delivered it in a way that was intended to ensure no pain or discomfort. For example, two participants said:

"It seems fine where I had it and no trouble at all. I thought the guy was very professional he knew what he was doing. When I had it before the GP did not really know what he was doing. He stuck the needle in our shoulder and started wiggling it round. But this Doctor numb it first and use the same needle to inject the steroid that was really good" (0052P 43-year-old male).

"I did enjoy it and I did not feel it, I did not feel any pain or discomfort when I had the injection" (0039L 67-year-old female). 
Very few participants said the outcome of the cortisone injection was not phenomenally successful, despite that, they still maintained that the way that the injections were performed was very professional. For example, one participant said:

"Your man who did the injection was polite and he knows what he was doing and everything else except this, I do not think the injection made any difference" (002L 43-year-old male).

Participants were asked about their preference of the injection site, whether they would have preferred it either from the side or the back of their shoulder. Most of them (from both injection groups) said they did not have a specific preference for the injection site; rather what they wanted was for the injection to improve their pain and shoulder function.

A few of the participants that did not have a particularly good successful outcome after the injection said they were not exactly sure if the outcome would have been any different if they had received it from a different site. However, when they were given the option of a repeat injection and they had the option of a second injection site and took it. For example, if a posterior route was initially unsuccessful then the repeat injection was performed via a lateral approach.

\section{Patient Education}

Most participants said that before the injections, they had anxiety about the reason for their shoulder pain because they lacked understanding of what was causing it. However, after their appointment with the injecting clinician, the participants said they were provided with good information regarding possible causes of their shoulder pain and received full explanations and advice on their care and treatment. The education they received also included individual home exercise programme (HEP), that involved the type, how many, how to do them, number of repetitions per exercise, and repetitions per day and when to do the exercises.

They said that this gave them a better understanding of their condition, the effects of the cortisone injection and what to do after the treatment. This further put their mind at ease and gave them the confidence to better use their shoulder without fear of causing more harm. They also expressed their appreciation of the way and manner things were explained to them, their involvement in the management of their care, which ultimately enhanced their overall improvement.

For example, one participant said that she will recommend the service to others because she found her shoulder pain was less alarming after she was given appropriate information regarding her condition and treatment. This highlights the significance of patient education on shoulder pain and shoulder injections, including aftercare advice and exercise information both in verbal and written forms, to shoulder pain patients receiving subacromial injection. This was echoed by one of the participants:

"Yes, there has been improvement. Hmm because everything was explained thoroughly to me and everyone was extremely helpful, so was not left wondering what was going to happen. Everything was explained to me and straight away I knew exactly what was going to happen and the staff were absolutely fantastic and the overall result has been very good so I would not say anything negative" (0027L 58 year old female).

Participants attributed their improvement in shoulder function not only to cortisone injection but also to the exercises that they were given by the injecting clinician. Providing exercise information meant that participants understood what to do, how to do them, when to do them and how many times to do them. Two participants said:

"The way the exercises were explained, and I have been doing it regularly. I have been doing it every day for past 3 weeks" (0034P 55-year-old female).

"Everything was great, the injection, the way he performed it, the knowledge I got, the exercises, the understanding of what was going on. I sort of push yourself. Knowing what is going on in the shoulder and what I need to do, and like I say I was treated well by everyone. I will sing the praise to everybody and I will go all day. I am trying to push our husband to have his done. I am glad it really improved it; I really am" (0031P 54-year-old female).

Table 5: Example of a Thematic Chart Showing the Views of two Participants during Interview

Thematic Chart 2: Patient Information and Advice

\begin{tabular}{|c|c|c|c|c|c|}
\hline & 2.1 & 2.2 & 2.3 & 2.4 & 2.5 \\
\hline $\begin{array}{l}\text { Participant ID, } \\
\text { Gender, Age, } \\
\text { Treatment } \\
\text { Group }\end{array}$ & $\begin{array}{l}\text { Explanation about } \\
\text { treatment and care }\end{array}$ & $\begin{array}{l}\text { Not knowing about the } \\
\text { shoulder problem }\end{array}$ & $\begin{array}{c}\text { Explanation of shoulder } \\
\text { problem }\end{array}$ & $\begin{array}{l}\text { Patient involvement } \\
\text { in their treatment }\end{array}$ & Exercise information \\
\hline $\begin{array}{l}\text { 0047L, Female } \\
64, \text { lateral } \\
\text { group }\end{array}$ & $\begin{array}{l}\text { I think it is just been } \\
\text { explained to, just the } \\
\text { general explanation } \\
\text { and feeling at ease }\end{array}$ & $\begin{array}{c}\text { Actually, I was scared } \\
\text { initially, I knew nothing } \\
\text { about the problem } \\
\text { before I went. It was } \\
\text { less alarming after you } \\
\text { got the experience of } \\
\text { explaining what it all } \\
\text { about }\end{array}$ & $\begin{array}{l}\text { Why they thought I was having } \\
\text { the problem and feeling I know } \\
\text { all about the problem because } \\
\text { actually I knew nothing about } \\
\text { the problem before I went and } \\
\text { generally feeling comfortable with } \\
\text { the treatment because it seemed } \\
\text { the right way to go. }\end{array}$ & $\begin{array}{l}\text { The whole experience } \\
\text { you know was very } \\
\text { easy and I wasn't at all } \\
\text { concerned after it had } \\
\text { all explained me. }\end{array}$ & $\begin{array}{c}\text { Been talked through } \\
\text { certain movements I } \\
\text { do and why it is not } \\
\text { working }\end{array}$ \\
\hline $\begin{array}{l}\text { 0031P, Female } \\
\text { 54, posterior } \\
\text { group }\end{array}$ & $\begin{array}{l}\text { Everything was } \\
\text { great, the injection, } \\
\text { the way he } \\
\text { performed it, the } \\
\text { knowledge I got, the } \\
\text { exercises }\end{array}$ & $\begin{array}{c}\text { Know what is going on in } \\
\text { the shoulder and what I } \\
\text { need to do. }\end{array}$ & $\begin{array}{l}\text { You know with you and the other } \\
\text { Doctor that did the injection } \\
\text { actually listened and you } \\
\text { explained. You know you felt like } \\
\text { you were a patient and you are } \\
\text { being listened to. }\end{array}$ & $\begin{array}{c}\text { When I come there } \\
\text { everything you said } \\
\text { made me feel like you } \\
\text { are being listened to. In } \\
\text { the hospital, they do not } \\
\text { seem to do that. }\end{array}$ & $\begin{array}{l}\text { I think where I had } \\
\text { the injection and I } \\
\text { followed the exercises } \\
\text { he gave me. I think the } \\
\text { combination of it all } \\
\text { improved the shoulder } \\
\text { itself }\end{array}$ \\
\hline
\end{tabular}


Citation: Ogbeivor C (2020) Qualitative Semi-Structured Interviews on the Experiences of Subacromial Impingement Syndrome Patients Receiving Shoulder Injections. Rea Int J of Ortho and Rheum. 1(1): 001-0013. DOI: 10.37179/rijor.000001.

Table 6: Example of using Framework for Descriptive and Classification Analysis.

\begin{tabular}{|c|c|c|c|}
\hline $\begin{array}{l}\text { Participant ID, } \\
\text { Gender, Age, } \\
\text { Treatment Group }\end{array}$ & $\begin{array}{l}\text { Column B } \\
\text { Data charted in column 3.5: Professionalism of } \\
\text { the injecting clinician }\end{array}$ & $\begin{array}{c}\text { Column C } \\
\text { Elements/Dimensions identified }\end{array}$ & $\begin{array}{l}\text { Column D } \\
\text { Categories/classes }\end{array}$ \\
\hline $\begin{array}{l}\text { 0052P, Male, } 43 \\
\text { Posterior group }\end{array}$ & $\begin{array}{l}\text { It seems fine where I had it and no trouble at all. I } \\
\text { thought the guy was very professional he knew what } \\
\text { he was doing. When I had it before the GP did not } \\
\text { really know what he was doing. He stuck the needle } \\
\text { in my shoulder and star } \\
\text { ted wiggling it round. But this Doctor numb it first } \\
\text { and use the same needle to inject the steroid, it was } \\
\text { really good. }\end{array}$ & $\begin{array}{l}\text { No problem with the injection site } \\
\text { Knowledge and skill of the injecting } \\
\text { clinician } \\
\text { Previous bad GP experience } \\
\text { The way the GP did the injection } \\
\text { The way the ESP performed the } \\
\text { injection } \\
\text { Injection outcome }\end{array}$ & $\begin{array}{l}\text { Positive injection experience } \\
\text { Professionalism of the injecting } \\
\text { ESP } \\
\text { Lack of GP's injection experience } \\
\text { GP's injection technique } \\
\text { ESP's injection technique } \\
\text { Successfully experience }\end{array}$ \\
\hline
\end{tabular}

Table 7: Example of using Framework for Descriptive and Classification Analysis.

\begin{tabular}{|c|c|c|c|}
\hline $\begin{array}{l}\text { Participant ID, } \\
\text { Gender, Age, } \\
\text { Treatment } \\
\text { Group }\end{array}$ & $\begin{array}{l}\text { Column B } \\
\text { Data charted in column 2.2: Not knowing about the } \\
\text { shoulder problem }\end{array}$ & $\begin{array}{l}\text { Column C } \\
\text { Elements/Dimensions } \\
\text { identified }\end{array}$ & $\begin{array}{c}\text { Column D } \\
\text { Categories/classes }\end{array}$ \\
\hline $\begin{array}{l}\text { 0014P, Male, } 47, \\
\text { Posterior group }\end{array}$ & $\begin{array}{l}\text { The pain started gradually, and pain in the shoulder } \\
\text { sort of gradually improved. I had constant pain initially } \\
\text { and not sure of the pain and when I had the injection } \\
\text { it brought down the pain level to } 7 / 10 \text { but it did not } \\
\text { go up any further since then but is sort of came down } \\
\text { gradually. At the same time, I had the psychology that } \\
\text { this was going to heal itself with time. Until then I was } \\
\text { not getting anywhere, and the pain was going up week } \\
\text { by week. Myself been a Nurse I was researching about } \\
\text { the condition quite a lot and I knew that the pattern } \\
\text { of pain was about } 24 \text { months. However, no matter } \\
\text { what you know about it, not been able to sleep at night } \\
\text { because of constant pain can be annoying. I was quite } \\
\text { relief that the pain has decreased. I will recommend } \\
\text { this to anyone, while it is does not give instant cure it } \\
\text { brings down the pain gradually. The time factor of } 18-20 \\
\text { months important, you never know whether it will take } \\
\text { the whole time". }\end{array}$ & $\begin{array}{c}\text { Felt he will get better with passage } \\
\text { of time } \\
\text { Took advantage of his profession } \\
\text { to investigate the problem } \\
\text { Pain lasting up to } 24 \text { months } \\
\text { Night pain affecting his sleep } \\
\text { Expression of pain irritation } \\
\text { Happy pain improved } \\
\text { Pain slowly improved } \\
\text { Could not guarantee complete } \\
\text { pain resolution with the injection } \\
\text { Relevance of time to pain }\end{array}$ & $\begin{array}{l}\text { Natural resolution of pain } \\
\text { Felt motivated to investigate the } \\
\text { cause of pain } \\
\text { Prognosis of the problem } \\
\text { Affected sleep } \\
\text { Sense of frustration with pain } \\
\text { Positive outcome } \\
\text { Gradual improvement of pain } \\
\text { Uncertainty about complete pain } \\
\text { resolution } \\
\text { Importance of prognosis }\end{array}$ \\
\hline $\begin{array}{l}\text { 0047L, Female 64, } \\
\text { Lateral group }\end{array}$ & $\begin{array}{l}\text { I was scared initially, I knew nothing about the problem } \\
\text { before I went. It was less alarming after you got the } \\
\text { experience of explaining what it all about. }\end{array}$ & $\begin{array}{l}\text { Fear of what was going on } \\
\text { Lack of knowledge about the } \\
\text { problem } \\
\text { Less frightening following } \\
\text { information about the problem }\end{array}$ & $\begin{array}{l}\text { Anxiety about the problem } \\
\text { Uncertainty about the cause of pain } \\
\text { Sense of reassurance following } \\
\text { education }\end{array}$ \\
\hline
\end{tabular}

\section{Access to Treatment}

Most of the participants said they were pleased at being treated in a community service because it was more local, easier, and quicker to access and parking was easier compared to the acute hospital. Although a few participants felt their appointment should have been sooner, most participants expressed their satisfaction for having a quicker appointment. They were also complimentary about the clinicians who treated them because they were not kept waiting for long periods of time before they were treated.

These comments included those that improved completely and those that had ongoing shoulder symptoms. Some participants spoke about their previous experience of going to the acute hospital for treatment. They said they had to travel a longer distance to get to the acute hospital and that they were kept waiting for long periods before being treated by the injecting ESP. For example, when two participants were asked if they would have preferred their treatment in the community or the acute hospital and they had this to say:

"In the community I think the hospital it so far, so long and you have to wait in the waiting room for hours and hours. Yours was well, fast, it was fast and really worked well. I thought I was coming for check-up and suddenly I had the treatment, I was overly impressed with it". (0055L 51-year-old female).

Oh no, in the community it was good. I got the appointment quick and was seen so quickly. I did not have to wait for too long. The location is fine because of the car park (0034P 55-year-old female).

Some participants also mentioned that they received a particularly good customer service and the phone calls for their appointments were polite and prompt. For example, one participant said:

"The experience regarding appointment time, phone call all 
particularly good. Very professional, 10 out 10 really for you because you've given out all the instructions of what to do (0056P 51-year-old male)".

However, there were a few participants who said they had difficulty contacting the service by telephone and could not speak to someone directly and that parking had been an issue.

All the comments above highlight the importance of locating a musculoskeletal service, such as the one where this study took place, within a central location in the community with easy access,

parking availability and good customer service. There were very few participants who did not mind where they received their treatment; rather what was more important to them was improvement of their shoulder symptoms.

\section{Discussion}

This study has highlighted the importance for clinicians and researchers to understand that the key expectation of patients with SAIS who have received subacromial cortisone injection is that they expect to see their shoulder symptoms improved or completely resolved so that they function more effectively. This is consistent with previous shoulder studies that found that reduction in shoulder pain and an increase in shoulder function were the most important reasons why patients with symptoms of shoulder pathology sought help from their doctor $[5,17]$.

This is particularly relevant in cases where physiotherapy and other conservative treatments such as cold or hot therapy have failed to improve symptoms of SAIS. This compares favourably with previous recommendations that subacromial injection should be the treatment choice for SAIS patients who have failed physiotherapy or where pain is limiting them from performing shoulder exercise (Hanchard et al 2004, Lewis 2011).

In this study it was discovered that those who had immediate and complete pain relief did not request physiotherapy and declined the option of physiotherapy because they would rather self-manage at home with exercises. This highlights the importance of the therapeutic effect of subacromial injection in improving pain and function in patients with SAIS thereby reducing clinical dependency and improving self-efficacy. However, some of the participants who said their improvement was gradual wanted some physiotherapy and were therefore offered it.

Participants that were interviewed confirmed that they were given adequate information and good explanations about their care and treatment by the injecting clinicians. According to the participants, patient education involved being listened to and being involved with decision making about their treatment, understanding the possible outcome of the treatment and being given exercise advice regarding the amount, frequency and duration of the exercise prescribed.

Some of the participants said that initially they had had anxiety about their condition and the treatment but that they were reassured after being listened to by the injecting physiotherapists who thoroughly explained their condition to them in manner they could easily understand. This highlights the contribution that patient education makes in enhancing the overall experience of treatment for shoulder patients and consequently improving their clinical outcomes. Research has shown that providing patients with education and information concerning their shoulder pain, its possible causes and diagnosis could ultimately prevent further deterioration and so enhance their improvement and self-efficacy [18].

The importance of patient education as a key factor in improving pain of musculoskeletal origin is consistent with other studies that have investigated the experiences and/or perceptions of patients with musculoskeletal conditions regarding physiotherapy treatment (Cooper et al 2008, DOH 2008, and Jones et al 2013). Although the participants were advised regarding a home exercise programme, to pace themselves, and avoid awkward lifting, they were also advised to exercise within their painful limits. A recent review suggests that treatment "protocols using painful shoulder exercises offer a small but significant benefit over pain-free exercises in the short term, with moderate quality of evidence" (Smith et al 2017).

In general, participants said that the information they received about their appointment together with quicker access to the service, also enhanced their experience. Some of the participants said that they felt that having quicker appointment times and being attended to prompt by the injecting clinician as well as receiving particularly good customer care contributed to their overall improvement.

However, a few participants felt that the information about their appointment was not clear enough and that they could have been seen sooner. Several authors reported that if patients with chronic musculoskeletal conditions are given faster and quicker access to treatment they are more likely to manage their condition better and be more independent thus avoiding unplanned hospital admissions and improving self-efficacy (DoH 2008) and Holdworth et al 2008) [19].

\section{Limitations of the Study}

The method of data collection in the qualitative study could be a weakness in this study. The semi-structured interview period was short and there were few variations in the amount of time spent on the interviews, with some participants having more time than others. This was due to time constraints at work, which could have reduced our ability to probe for more in-depth responses which are necessary for obtaining richer data (Patton 1990) [20]. However, we did try to try to ensure that enough information was gathered from the participants during the interviews. I also used respondent revalidation by sending the transcript back to the participants to ensure that its contents matched what had been said.

\section{Implications for Practice}

This study highlights the importance of involving patients with musculoskeletal problems in all aspects of their care and treatment to enhance their overall experience and improve treatment outcomes. However, another study (Jones et al 2013) noted that there are instances where there is a serious mismatch between clinicians and patients' perception of the impact of shoulder problem. Therefore, both the patients and the treating physiotherapy should on the same page regarding information, explanations, and advice on the plan of care and treatment [21]. 
This information should address decision making processes of patients' care and management and any questions they have about their care should be thoroughly explained to them. The information should be clear including aftercare advice and exercise instruction both in verbal and written forms, to shoulder pain patients receiving subacromial injection.

There is the need for shoulder injecting clinicians to be knowledgeable not only of the condition they are treating but also of the injection procedure and to delivered it in a way that is intended to ensure no pain or discomfort. Strategies for training injecting clinicians are required, in order provide adequate experience and skills. The Association of Chartered Physiotherapists in Orthopaedic Medicine \& Injection Therapy (ACPOMIT, 1999) clinical guidelines for soft tissue and joint injections is a good reference [22-26].

\section{Conclusions}

To our knowledge, this is the first study that used a mixed methods research design that combines a pragmatic RCT to investigate the effectiveness of shoulder injections and a semi structured qualitative interviews to explore the experiences of the patients receiving the injections.

This study has demonstrated that participants with SAIS felt that their shoulder pain and function improved not only because of the effect of the shoulder injection, but also because of the education about SAIS and subacromial injection, exercise information, the experience and the professionalism of the injecting clinicians, as well as the way and manner in which the injections were performed. Others include quicker access to care.

\section{Acknowledgements}

The author wishes to thank Dr Sheila Black and Professor David Pavelin both of whom were his academic supervisors for his doctor of physiotherapy study. The authors wish to thank all patients who participated in the study, and to all collaborating physiotherapists and all staff involved in patient recruitment and data collection. The authors also wish to thank additional members of the project steering group - Karen Denton, Jonathan Shrewsbury, James Trotman and Tamara Pillay all of whom contributed immensely to the success of this research.

Ethical approval: Approval was obtained from the Research Ethics Committee (REC) London Centre, UK on 16/4/2014 (REC reference 14/LO/0406). Written informed consent, a prerequisite for study participation, was obtained from all participants.

Funding: This study forms part of the work included in the $\mathrm{PhD}$ thesis (conferred July 2017) of CO at the University of Essex, Colchester, UK. This research did not receive any grant from funding agencies in the public, commercial or not-for-profit sectors.

\section{Highlights}

- This study highlights the importance of involving patients with musculoskeletal problems in all aspects of their care and treatment to enhance their overall experience and improve treatment outcomes. However, another study (Jones et al 2013) noted that there are instances where there is a serious mismatch between clinicians and patients' perception of the impact of shoulder problem. Therefore, both the patients and the treating physiotherapy should on the same page regarding information, explanations, and advice on the plan of care and treatment.

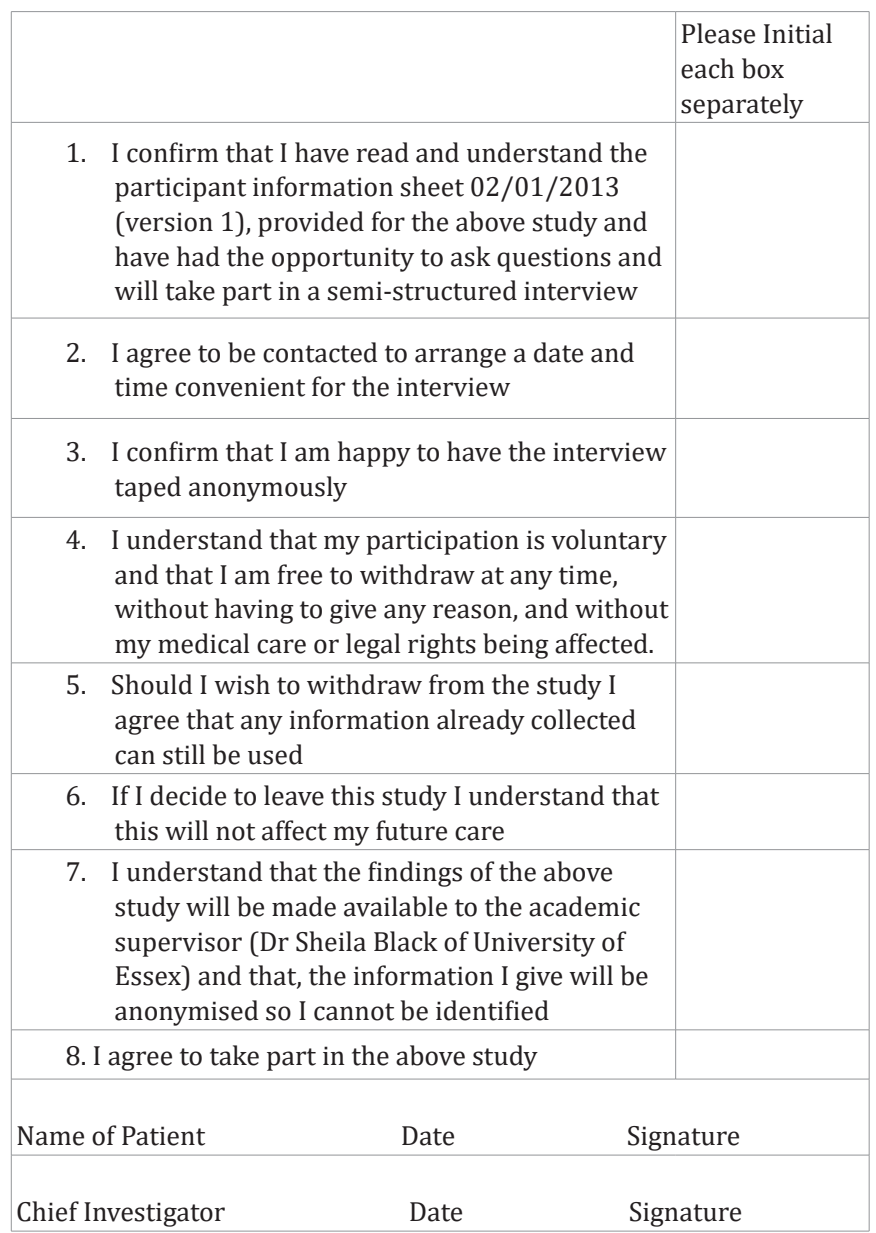

- This information should address decision making processes of patients' care and management and any questions they have about their care should be thoroughly explained to them. The information should be clear including aftercare advice and exercise instruction both in verbal and written forms, to shoulder pain patients receiving subacromial injection.

- There is the need for shoulder injecting clinicians to be knowledgeable not only of the condition they are treating but also of the injection procedure and to delivered it in a way that is intended to ensure no pain or discomfort. Strategies for training injecting clinicians are required, in order provide adequate experience and skills. The Association of Chartered Physiotherapists in Orthopaedic Medicine \& Injection Therapy (ACPOMIT, 1999) clinical guidelines for soft tissue and joint injections is a good reference. 
Citation: Ogbeivor C (2020) Qualitative Semi-Structured Interviews on the Experiences of Subacromial Impingement Syndrome Patients Receiving Shoulder Injections. Rea Int J of Ortho and Rheum. 1(1): 001-0013. DOI: 10.37179/rijor.000001.

This study also highlights the importance of involving patients in shoulder research and recruiting them from care settings where the condition is been treated.

\section{Appendices}

Appendix 1: Qualitative Semi-structured Study - Consent Form

Title of Project: What are the experiences of patients with shoulder pain experiencing side versus back approach to shoulder injections?

Name of Chief Investigator: Collins Ogbeivor

\section{Appendix 2: Qualitative Semi-Structured Questions}

1. Tell me about your overall experience since receiving the injection

2. What would say made your shoulder pain got better, worse, or the same after receiving the injection?

3. If given the choice would have preferred your injection from the side or the back of the shoulder? Why did you answer that way?

4. Now that you have had your treatment, how did you find the experience?

5. What are your experiences concerning your patient care from when your GP referred you to this service?

6. If provided with the opportunity, would you have preferred to have the injection in the acute trust or in the community? Why did you answer that way?

7. Would you recommend this treatment to a friend or relative who had the same problem? Why did you answer that way?

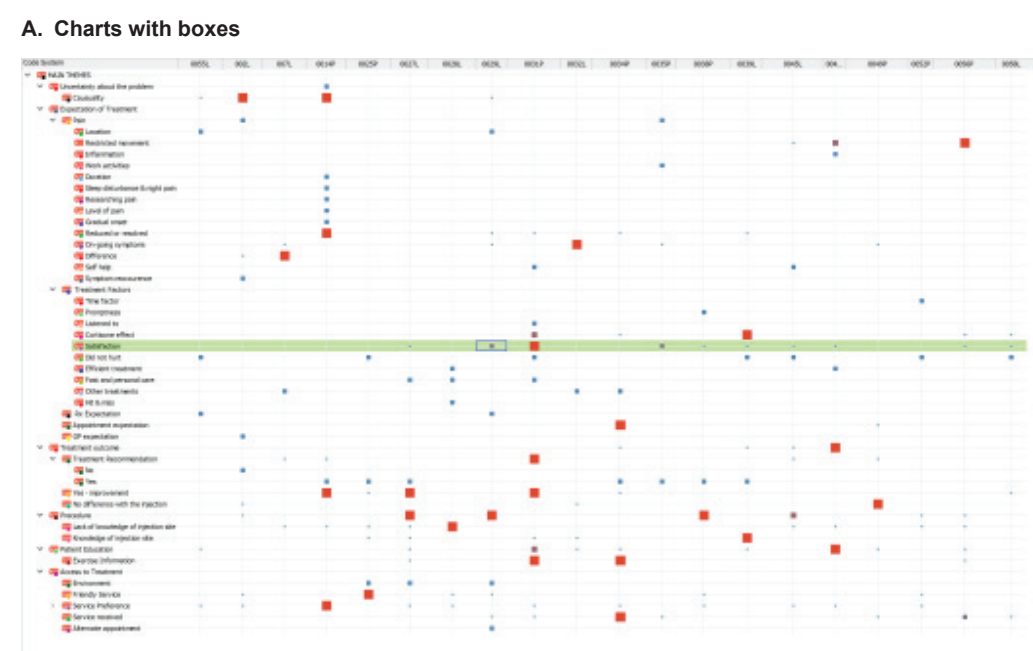

Keys: Boxes represent number of codes

B. Charts with number codes

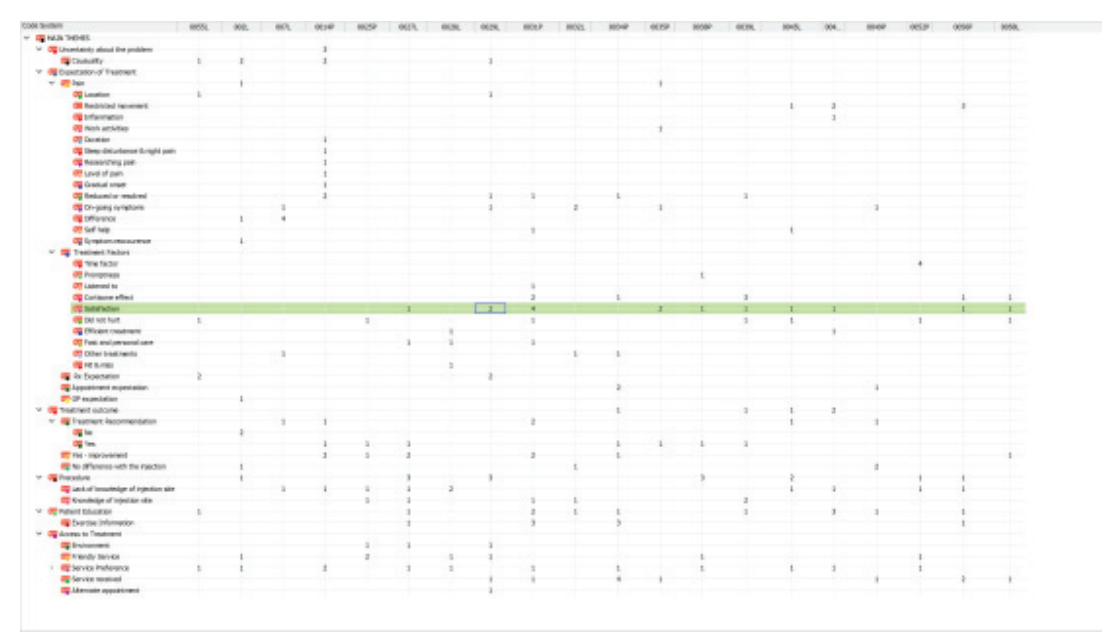

Keys: Numbers represent codes 
Citation: Ogbeivor C (2020) Qualitative Semi-Structured Interviews on the Experiences of Subacromial Impingement Syndrome Patients Receiving Shoulder Injections. Rea Int J of Ortho and Rheum. 1(1): 001-0013. DOI: 10.37179/rijor.000001.

\section{References}

1. Association of Chartered Physiotherapists in Orthopedic Medicine and Injection Therapy (ACPOMIT 1999) A clinical guideline for the use of injection therapy by physiotherapists. Link: https://bit.ly/32jEexq

2. Carter B (2002) 'Clients' experiences of frozen shoulder and its treatment with Bowen technique' Complement Therapy Nursing Midwifery 8: 204-210. Link: https://bit.ly/32noCch

3. Chester R, Jerosch-Herold C, Lewis J, Shepstone L (2016) 'Psychological factors are associated with the outcome of physiotherapy for people with shoulder pain: a multicenter longitudinal cohort study' British Journal of Sports Medicine. Link: https://bit.ly/32o9Emr

4. Department of Health (2008) Self-referral pilots to musculoskeletal physiotherapy and the implications for improving access to other AHP services. London: Department of Health. Link: https://bit.ly/32kpbDE

5. Department of Health (2009) NHS 2010-2015: from good to great. Preventative, people centered, productive. London: DH. Link: https:// bit.ly/2EoSdKo

6. Fashanu B (2014) A qualitative analysis of patients' expectations and experiences of physiotherapy in the management of their shoulder pain, PHD thesis. University of Essex.

7. Goel V, Dabke H, Gajjar S, Jones A, Kulkarni R (2012) 'Accuracy of two methods of subacromial shoulder injection: a prospective randomized control trial' Orthopedic Proceedings 94 (SUPP IV) 87. Link: https:// bit.ly/3hvKqIZ

8. Harrison K, Williams S (2000) 'Exploring the power balance in physiotherapy' British Journal of Therapy Rehabilitation 7: 355-361. Link: https://bit.ly/2CWAr0g

9. Henkus HE, Cobben LP, Coerkamp EG, Nelissen RG, van Arkel ER (2006) 'The accuracy of subacromial injections: a prospective randomized magnetic resonance imaging study' Arthroscopy 22: 277282. Link: https://bit.ly/3aY7UUw

10. Holdsworth LK, Webster VS, McFadyen AK (2008) 'Are patients who refer themselves to physiotherapy different from those referred by GPs? Results of a national trial and The Scottish Physiotherapy SelfReferral Study Group 'Physiotherapy 94: 236-243. Link: https://bit. ly/3jeDNLw

11. Jones S, Hanchard N, Hamilton S, Rangan A (2013) 'A qualitative study of patients' perceptions and priorities when living with primary frozen shoulder' British Medical Journal 3: 1-9. Link: https://bit.ly/3lpKqwL

12. Kang MN, Rizio L, Prybicien M, Middlemas DA, Blacksin MF (2008) 'The accuracy of subacromial corticosteroid injections: a comparison of multiple methods' Journal of Shoulder \& Elbow Surgery 17: 61-66. Link: https://bit.ly/34uYGy4
13. Marder RA, Kim HS, Labson DJ, Hunter JC (2012) 'Injection of the Subacromial Bursa in Patients with Rotator Cuff Syndrome. A prospective, randomized study comparing the effectiveness of different routes' Journal of Bone and Joint Surgery 94: 1442-1447. Link: https://bit.ly/3gupIbg

14. Mason J (2002) Qualitative Researching (2 ${ }^{\text {nd }}$ edition) London: Sage Publications. Link: https://bit.ly/3aVJ7R3

15. Minns Lowe CJ, Moser J, Barker K (2014) 'Living with a symptomatic rotator cuff tear "bad days, bad nights": a qualitative study' $B M C$ Musculoskeletal Disorders 15: 228. Link: https://bit.ly/32mvG9a

16. Nyman P,Palenius K, Panula H, Mälkiä E (2012) 'Patients' experiences of shoulder problems prior to and following intervention' Physiotherapy Theory Practice 28: 221-231. Link: https://bit.ly/3jeBAje

17.Patton MQ (2002) Qualitative Evaluation and Research Methods ( ${ }^{\text {rd }}$ edition) London: Sage Publications. Link: https://bit.ly/3aWesDe

18. Ritchie J, Lewis J (2003) Qualitative Research Practice: A Guide for Social Science Students and Researchers London: SAGE Publications. Link: https://bit.ly/3gtQsbC

19. Ritchie J, Spencer E (1994) Qualitative data analysis for applied policy research. In Bryman A \& Burgess RG (eds) Analysing Qualitative Data London: Routledge. 9: 22. Link: https://bit.ly/3hwzVFe

20. Rowell RM, Polipnick JA (2008) 'A pilot mixed methods study of patient satisfaction with chiropractic care for back pain' Journal of Manipulative and Physiological Therapeutics 31: 602- 610. Link: https://bit.ly/3aSIKa4

21. Saunders S, Longworth S (2012) Injection Techniques in Orthopedics and Sports Medicine: A practical manual for doctors and physiotherapists ( $3^{\text {rd }}$ edition) London: Elsevier. Link: https://bit.ly/3hoaR3j

22. Sardelli M, Burks RT (2008) 'Distances to the subacromial bursa from 3 different injection sites as measured arthroscopically’ Arthroscopy 24: 992-996. Link: https://bit.ly/34txq2Z

23. Shanahan EM, Sladek R (2011) 'Shoulder pain at the workplace' Best Practice Research Clinical Rheumatology 25: 59-68. Link: https://bit. ly/2CYdLwN

24. Shaw JA, Connelly DM, Zecevic AA (2010) 'Pragmatism in practice: Mixed methods research for Physiotherapy' Physiotherapy Theory and Practice 26: 510-518. Link: https://bit.ly/2FRyByN

25. Tongco MDC (2007) 'Purposive sampling as a tool for informant selection' Ethnobotany Research \& Applications 5: 147-158. Link: https://bit.ly/2Qpq3S4

26. Van der Windt DAWM, Thomas E, Pope DP, de Winter AF, Macfarlane GJ, et al. (2000) 'Occupational risk factors for shoulder pain: a systematic review' Occupational \& Environmental Medicine 57: 433442. Link: https://bit.ly/2YwE44C 